\title{
Minimizing Impact of the Urbanization on the Physical Habitat Suitability of Downstream River by a Multi-objective Optimization
}

Mahdi Sedighkia ( $\square$ mahdi.sedighkia@my.jcu.edu.au )

James Cook University

Asghar Abdoli

Esri

\section{Research Article}

Keywords: Stormwater management, Urbanization, physical habitat loss, ANFIS, MOPSO

Posted Date: May 24th, 2021

DOI: https://doi.org/10.21203/rs.3.rs-445145/v1

License: (c) (i) This work is licensed under a Creative Commons Attribution 4.0 International License.

Read Full License 


\title{
Minimizing impact of the urbanization on the physical habitat suitability of
} downstream river by a multi-objective optimization

\author{
Mahdi Sedighkia ${ }^{1 *}$, Asghar Abdoli ${ }^{2}$ \\ 1-College of science and engineering, James Cook University, Australia \\ 2-Environmental science research institute, Iran \\ *Corresponding Author: Mahdi.sedighkia@my.jcu.edu.au
}

\begin{abstract}
\end{abstract}
Urbanization might considerably change outflow of catchment that might affect physical habitat suitability at downstream river ecosystem. Present study proposes and evaluates an applicable method to minimize impact of urbanization on the suitability of physical habitats in which habitat loss and area of the urban region are optimized. coupled particle swarm optimization- adaptive neuro fuzzy inference system is used to simulate runoff in the structure of a multi-objective metaheuristic optimization. Fuzzy physical habitat simulation was applied to simulate suitability of physical habitats. Different measurement indices including the Nash-Sutcliffe model efficiency coefficient, root means square error and vulnerability index were utilized to measure performance of the simulation-optimization system. Based on the results in the case study, the proposed system is able to mitigate physical habitat impacts by optimizing area of the urban region. Regional government had planned to urbanize $90 \%$ of the catchment area. However, it damages physical habitats considerably. The optimal plan reduced the urban area to $56 \%$ and minimized physical habitat loss. This method is able to reduce negotiations between regional governments and environmental advocators for development of the new urban areas in terms of minimizing physical habitat loss in river ecosystems.

Key words: Stormwater management, Urbanization, physical habitat loss, ANFIS, MOPSO 
24 Stormwater is mainly defined as runoff that originates from the rain including snow and ice melt. The 25 most generated runoff is directly conveyed to the rivers or other water bodies (Jefferson et.al, 2017). One 26 of the main tasks for the civil engineers in the urban management is appropriate management of the 27 stormwater. In other words, stormwater management might be defined as controlling the surface runoff to 28 reduce water pollution and restore ecosystem integrity (Shishegar et.al, 2018). Urbanization is one of the 29 main challenges in the stormwater management. Because, the primary effect of the urbanization is 30 increasing impervious surfaces compared with previous surfaces (Kong et.al, 2017). In other words, 31 urbanization increases surface runoff to the river ecosystems. Owing to importance of the stormwater 32 management in the urban areas, different hydrodynamic and hydrologic models have been developed to 33 improve management of the urban areas.

34 As a review on the used models in the urban water management, two models including SWMM and 35 MUSIC are briefly reviewed. The EPA Storm Water Management Model (SWMM) is one of the 36 applicable models for simulating urban water quality and quantity. This model is mainly applied in the 37 post-development runoff, surface drainage hydraulics, detention pond design, low impact development, 38 runoff water quality, runoff treatment, dual drainage systems, combined sewer overflows and continuous 39 simulations (Gironás et.al, 2010).Moreover, MUSIC is the Model for Urban Stormwater Improvement 40 Conceptualization. In fact, MUSIC is a decision-making system that enables engineers for evaluating 41 conceptual designs of the stormwater management systems. MUSIC applies a risk-based approach in 42 which three main examinations are carried out as follows (eWater, 2011).

43 1) Examination of the treatment system in terms of peak flow reduction, volumetric reduction and 44 frequency of event flows

45 2) Examination of the response of the aquatic ecosystems to pollutant concentrations above a pre-defined 46 threshold level 
47 3) Examination of the long-term mean annual pollutant load delivered to the stream or river as the 48 outflow of the catchment.

49 These models have been applied in different projects across the world. However, two weakness points 50 should be noted regarding these models and other similar models. First, they could not be used in the 51 structure of the advanced optimization algorithm. In other words, it is required to develop urban water 52 model in the structure of the optimization systems for improving the optimization processes in the 53 stormwater management. Hence, soft computing methods might be an appropriate solution to develop 54 surface runoff models for the optimization applications in the stormwater management. Moreover, these 55 models only addressed the impact of the water quality on the river ecosystem without considering 56 physical habitat impacts that might be important and vital.

57 Powerful computers provide a huge capacity to use advanced computational methods. Artificial 58 intelligence methods (AI) were the significant step to improve simulation and optimization methods that 59 have been utilized for the engineering applications extensively. Artificial neural networks have widely 60 been used in the hydrologic simulations. For example, they have successfully been applied to forecast 61 stream flow or inflow of the reservoirs (e.g Kisi et.al, 2007; Mehr et.al, 2015; Niu et.al, 2021). Owing to 62 some drawbacks of these methods such as acting as black box, improving neural networks was necessary 63 to increase efficiency and interpretability. Neuro fuzzy inference systems might have advantages of the 64 both fuzzy inference systems and neural networks. Thus, they have been highlighted in the literature to 65 simulate environmental and hydrologic phenomena. Adaptive neuro fuzzy inference system (ANFIS) is 66 an applicable data driven model that applies a fuzzy inference systems in the structure of the neural 67 network. ANFIS based model have been used in the previous studies to predict hydrologic parameters 68 such as stream flow (e.g Riahi-Madvar et.al, 2021; Dalkiliç et.al, 2020; Adnan et.al, 2020). Results 69 indicate that ANFIS based models are effective to improve efficiency of the forecasting systems in the 70 hydrology. 
71 Evolutionary algorithms are one of the advanced methods for optimization processes in the engineering.

72 For example, they have been used in the reservoir operation optimization (e.g Ehteram et.al, 2018; Afshar 73 et.al, 2007; Haddad et.al, 2015; Haddad et.al, 2016). Some algorithms such as the genetic algorithm have 74 been utilized in many problems (Mirjalili et.al, 2020). For example, GA was applied to improve cost75 effective methods in the urban water management coupled with MUSIC (Montaseri et.al, 2015). 76 Evolutionary algorithms might be classified in two classes including classic and new generation 77 algorithms (Dokeroglu et.al, 2019). Classic algorithms including GA and particle swarm optimization 78 (PSO) could provide proper response in many engineering problems. New generation algorithms such as 79 bat algorithm (BA) have been developed to improve efficiency of the metaheuristic optimization (Yang 80 et.al, 2013). However, classic algorithms might provide robust response in some cases. The main 81 framework of these algorithms is the same though they use different strategies to search the solution 82 space.

83 The main impact of increasing stormwater might be on the aquatic habitats in the river ecosystem 84 including two aspects. First, Urbanization might increase water pollutants in the stormwater that might be 85 harmful for the aquatics such as fishes. Another impact that might not be focused in the first glance is on 86 the physical habitats. It is required to review on the concept of the physical habitat to clarify the problem. 87 Initial concept of the physical habitat simulation has been developed by the instream flow incremental 88 methodology (IFIM) (Bovee et.al, 1998). Some methods such as univariate method simulate suitability 89 of the physical habitat parameters including depth, velocity and substrate separately. Then, mathematical 90 models are used to compute combined suitability (Sedighkia et.al, 2021). Owing to importance of 91 improving univariate method, multivariate fuzzy logic approach has been developed (Sedighkia et.al, 92 2021). Previous studies demonstrated applicability and efficiency of the fuzzy physical habitat simulation 93 to assess physical habitat loss in the river habitats with a focus on fishes as one of the main species in 94 many rivers (Noack et..al, 2013). 
Present study proposes a novel framework to minimize impacts of the urbanization on the physical habitat suitability in which an integrated simulation-optimization method is developed. ANFIS based model is applied to simulate runoff in the catchment scale. Fuzzy physical habitat simulation was utilized to assess the physical habitat loss. Multi-objective particle swarm optimization (MOPSO) was utilized to optimize the developing urban area in the catchment. Present study might open a new window to apply novel optimization methods for stormwater management considering advanced concepts of the physical habitats in the development of the urban areas. In fact, the proposed framework might demonstrate how advanced optimization methods can open new windows to solve complex problems in the ecohydrology and ecohydraulics. The proposed framework is upgradable to solve other complex problems in the river basin scale.

\section{2- Application and methodology}

\section{2-1- Surface runoff modeling}

We applied an ANFIS based model to simulate runoff in the catchment scale. Many factors might be effective to generate surface runoff in the catchments. However, some factors might be considered as the main effective factors in the data driven model. For example, total rainfall, area and slope of the subcatchment or catchment and land use might be the most important parameters in this regard. Owing to using ANFIS based model, it is necessary to describe the structure of the ANFIS. Figure 1 displays a 112 simple structure of the ANFIS in which two inputs have been considered. Five layers could be seen in the 113 structure of the ANFIS. In the first layer, input membership functions were computed. Fixed nodes in the 114 second layer compute output as product of all incoming signals. Then, normalized firing output as product 115 of all incoming signals is calculated in the third layer. Fourth layer includes adaptive parameters that are 116 tuned during the training process. The overall output as the summation of all incoming signals is finally 117 assessed in the final layer. More details on the formulation of the ANFIS model has been addressed in the 118 literature (Azamathulla et.al, 2009). 


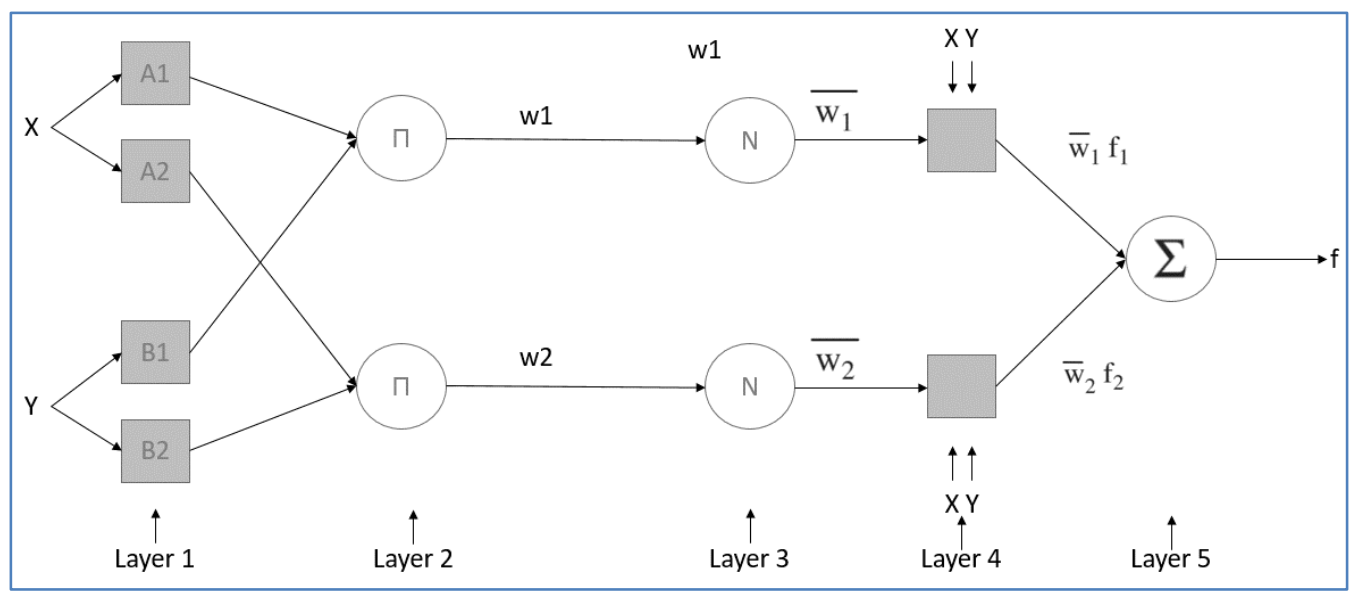

Figure 1-Simple structure of ANFIS based data driven model

121 Using evolutionary algorithms in the training process of the ANFIS based model might improve accuracy

122 of the models. Thus, we utilized PSO to train the data driven model. In other words, surface runoff was

123 simulated using a PSO-ANFIS model. The flowchart of the PSO-ANFIS is displayed in the figure 2.



124 
Table 1 displays the main characteristics of the developed ANFIS based model in the proposed

127 framework. Selecting of the inputs is the most important step to develop a correct data driven model. We

128 selected six inputs in the developed method including total rainfall, total area of the catchment or sub-

129 catchment, slope of the catchment or sub-catchment, curve number of the urban areas and curve number

130 of the non-urban areas and percentage of the urbanized area. It should be noted initial assessment of the

131 case study demonstrated that non-urban areas are mainly agricultural lands and mixed forests.

\begin{tabular}{|c|c|c|c|c|c|c|}
\hline Inputs & $\begin{array}{l}\text { Number } \\
\text { of MFs } \\
\text { (inputs) }\end{array}$ & $\begin{array}{l}\text { Type of } \\
\text { MFs } \\
\text { (inputs) }\end{array}$ & Outputs & $\begin{array}{c}\text { Number of } \\
\text { MFs } \\
\text { (Output) }\end{array}$ & $\begin{array}{l}\text { Type of } \\
\text { MFs } \\
\text { (Output) }\end{array}$ & $\begin{array}{l}\text { Clustering } \\
\text { method }\end{array}$ \\
\hline Total rainfall (mm) & 10 & Triangular & Outflow & 10 & Triangular & Subtractive \\
\hline $\begin{array}{l}\text { Total area of the } \\
\text { catchment or sub- } \\
\text { catchment }(\mathrm{Ha})\end{array}$ & 10 & Triangular & $\begin{array}{l}\text { from the } \\
\text { catchment } \\
\text { or sub- }\end{array}$ & & & Clustering \\
\hline $\begin{array}{l}\text { Average slope of the } \\
\text { catchment or sub } \\
\text { catchment }(\%)\end{array}$ & 10 & Triangular & $\begin{array}{c}\text { catchment } \\
\text { (L/S) }\end{array}$ & & & \\
\hline $\begin{array}{l}\text { Curve number }(\mathrm{CN}) \\
\text { for the urban areas }\end{array}$ & 10 & Triangular & & & & \\
\hline $\begin{array}{l}\text { Curve number }(\mathrm{CN}) \\
\text { for the non-urban areas }\end{array}$ & 10 & Triangular & & & & \\
\hline $\begin{array}{l}\text { Percentage of the } \\
\text { urbanized area (\%) }\end{array}$ & 10 & & & & & \\
\hline
\end{tabular}


134 Each data driven model needs some indices to measure the robustness of the model. Two indices 135 including the Nash-Sutcliffe model efficiency coefficient (NSE) and root mean square error (RMSE)

136 were applied to measure predictive skills of the runoff data driven model as displayed in the following 137 equations. NSE is originally developed for the hydrologic models (Gupta et.al, 2009). Thus, it is 138 applicable in the present study.

$139 \quad N S E=1-\frac{\sum_{t=1}^{T} a b s\left(O B S_{t}-S I M_{t}\right)}{\sum_{t=1}^{T} a b s\left(O B S_{t}-O B S m\right)}$

$140 \quad R M S E=\sqrt{\frac{\sum_{t=1}^{T}\left(S I M_{t}-O B S_{t}\right)^{2}}{T}}$

141 where $\mathrm{OBS}_{\mathrm{t}}$ is observed or recorded data in the time step $\mathrm{t}, \mathrm{SIM}_{\mathrm{t}}$ is the simulated data by the model and T

142 is total number of time steps.

\section{2-2-Optimization system}

144 The main purpose of the optimization system is to minimize physical habitat loss in which the area of the 145 urban region is optimized. On the one hand, the regional government might aim maximum development 146 of the urban areas. On the other hand, there is a serious concern regarding impacts of the increasing 147 surface runoff on the physical habitat loss in the stream ecosystem. It should be noted that based on the 148 initial survey in the case study, it was demonstrated that current physical habitat suitability is close to the 149 natural flow. The main component of each optimization system is the objective function. Two objective 150 functions were developed including physical habitat loss objective function and urban area objective 151 function as displayed in the following equations. In fact, first objective function is responsible to reduce 152 concerns of the environmental advocators. Conversely, the second objective function would maximize the 153 developing urban area that is aimed by the regional government.

154 Objective funcion $1=\sum_{t=1}^{T}\left(\frac{N W U A C_{t}-N W U A F_{t}}{s c c_{t}}\right)^{2}$ 
where $\mathrm{NWUAC}_{t}$ is normalized weighted useable area in the current condition, $\mathrm{NWUAF}_{t}$ is normalized

157 weighted useable area in the future condition or initial urbanization plan, MUR is maximum percentage of 158 the urban area based on the initial plan in the catchment and OUR $\mathrm{t}_{\mathrm{t}}$ is optimized percentage of the 159 urbanized area. Figure 3 displays fuzzy physical habitat simulation method that is used in the present study. More details have been addressed in the literature (Noack et..al, 2013)..

161



Figure 3- flowchart of the physical habitat simulation in the proposed framework

Owing to development of two objective functions in the optimization system, a multi- objective optimization algorithm is required. We selected one of the known multi objective metaheuristic algorithms to optimize surface runoff considering physical habitat impacts. Multi-objective particle swarm optimization (MOPSO) has been applied in the optimization problems successfully. Figure 4 displays flowchart of this algorithm. More details of this optimization algorithm have been addressed in the literature (Coello et.al, 2004). It is essential to apply some indices to measure performance of the optimization system in terms of mitigating physical habitat loss as the main purpose of the optimization 
170 model. Two indices including RMSE and vulnerability index was utilized in this regard. Equations 6 and

1717 display these indices.

$172 \quad R M S E_{\text {habitat loss }}=\sqrt{\frac{\sum_{t=1}^{T}\left(N W U A C_{t}-N W U A F_{t}\right)^{2}}{T}}$

$173 \quad$ Vulnrability index $x_{\text {habitat loss }}=M A X \frac{\left(N W U A C_{t}-N W U A F_{t}\right)}{N W U A C_{t}}$

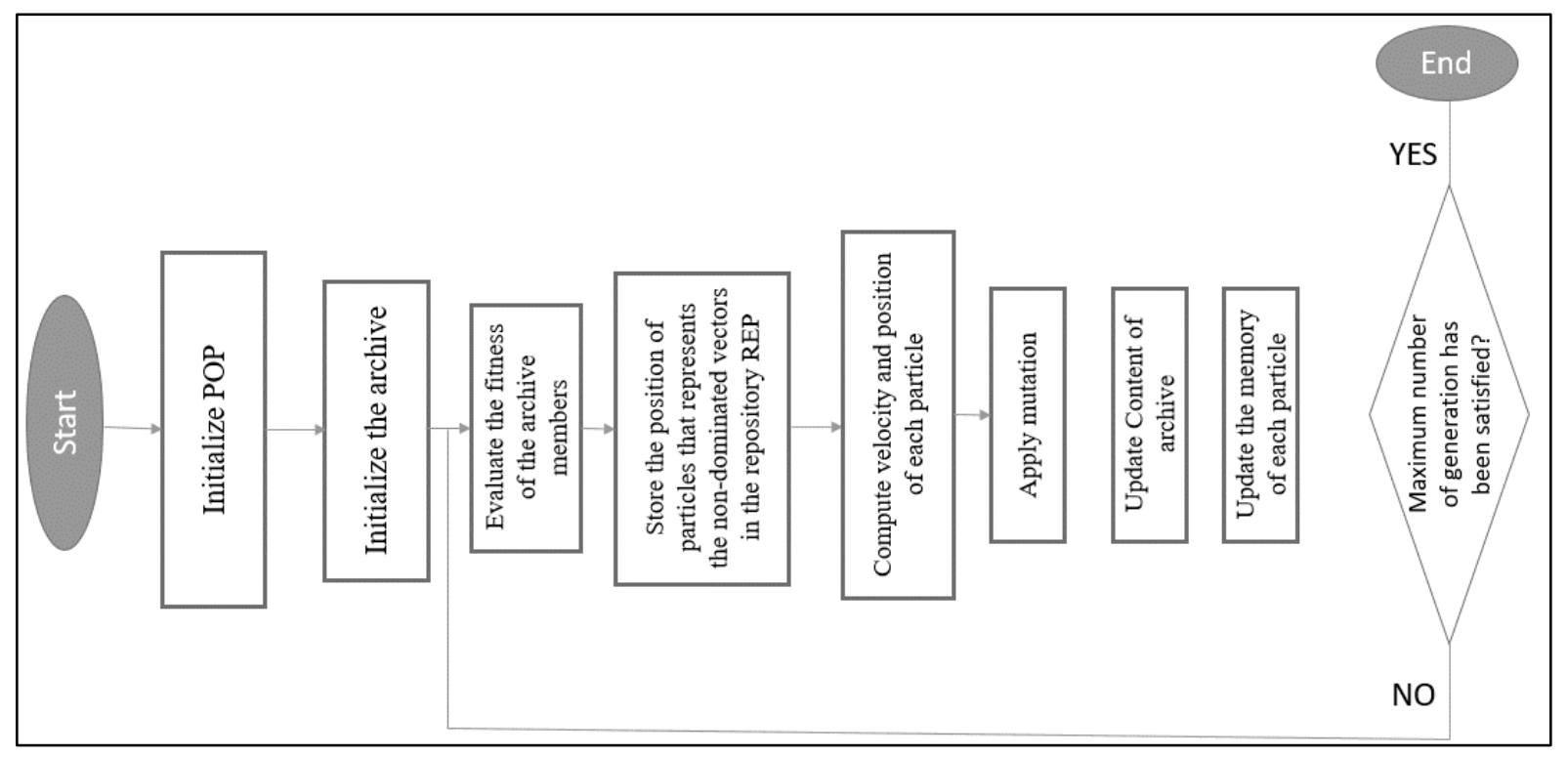

\section{2-3-Case study}

178 Tajan River is one of the important rivers in the southern Caspian Sea basin in Iran. This river basin is

179 one of the popular regions for living in the country due to appropriate weather condition. Hence, 180 urbanization is a challenge in this river basin. In other words, increasing population raises needs for more 181 urbanizing areas that mean impervious areas will be increased. Figure 5 displays river network and land 182 use of this river basin. A target sub-basin was selected for the present study as displayed in the figure 5. 
184 catchment are shown in the table 2.



Figure 5- Land use, location of the Rajaei reservoir and river network map of Tajan basin

Table 2- Main characteristics of the sub-catchments in the target sub-basin

\begin{tabular}{|c|c|c|c|}
\hline Sub-catchment & & & Main land \\
code & Area & Average & current \\
& (Ha) & slope (\%) & condition \\
\hline 1 & 35.96 & 4.36 & Agriculture \\
\hline
\end{tabular}




\begin{tabular}{|c|c|c|c|}
\hline 2 & 47.63 & 4.48 & Agriculture \\
\hline 3 & 3.58 & 3.89 & Agriculture \\
\hline 4 & 118.35 & 3.78 & Agriculture \\
\hline 5 & 227.53 & 3.73 & Agriculture \\
\hline 6 & 57.54 & 4.00 & Agriculture \\
\hline 7 & 202.12 & 3.75 & Agriculture \\
\hline 8 & 71.60 & 3.43 & Urban \\
\hline 9 & 123.99 & 3.63 & Urban \\
\hline 10 & 47.19 & 12.16 & Forest \\
\hline 11 & 108.31 & 6.62 & Agriculture \\
\hline 12 & 123.74 & 10.52 & Forest \\
\hline 13 & 20.46 & 12.15 & Forest \\
\hline 14 & 48.82 & 14.21 & Forest \\
\hline 15 & 137.61 & 4.35 & Agriculture \\
\hline 16 & 8.91 & 2.72 & Agriculture \\
\hline 17 & 313.75 & 9.86 & Forest \\
\hline 18 & 75.80 & 9.21 & Agriculture \\
\hline 19 & 9.16 & 2.98 & Agriculture \\
\hline 20 & 1.07 & 3.91 & Agriculture \\
\hline 21 & 53.46 & 8.56 & Agriculture \\
\hline 22 & 54.78 & 2.90 & Agriculture \\
\hline 23 & 76.62 & 8.28 & Agriculture \\
\hline 24 & 96.07 & 5.74 & Agriculture \\
\hline 25 & 136.11 & 4.70 & Agriculture \\
\hline
\end{tabular}


Recorded data at outflow of the sub-catchments and catchments were utilized to develop the data driven model. Eighty percent of the total recorded data was used to train the model. Testing process was carried out in different sub-catchments and the catchment. It should be noted that it is required to test predictive 192 skills of the model considering changing area of the catchment and land use. Hence, two main sub193 catchments including a non-urban and an urban sub-catchment were selected for testing process. 194 Moreover, testing process was carried out in the catchment. Based on the Table 2, urban areas in the 195 catchment are limited in the current condition (close to 9\% of the catchment). However, regional 196 government plans to increase urban areas to $90 \%$ of the catchment due to increasing population. On the 197 other hand, environmental advocators have serious concerns regarding physical habitats of the 198 downstream river of the catchment. It is an important reproduction habitat for the native fish species. In 199 fact, increasing rate of flow due to urbanization at the downstream river might raise physical habitat loss 200 for the fish species. Hence, there is a challenging conflict between two objectives. In other words, it is necessary to optimize area of the developing urban region considering environmental impacts.

\section{3-Results and Discussion}

204 In the first step, it is necessary to present results of the data driven model to simulate runoff in the scale of 205 the catchment and sub-catchments. Two sub-catchments were selected to demonstrate ability of ANFIS 206 based model to simulate outflow in the simulated period. It should be noted that these sub-catchments 207 were different in terms of land use. In other words, one of them mainly includes non-urban areas. 208 Conversely, second sub-catchment mainly includes urban areas. Figures 6 and 7 display the training and 209 testing processes of the model in these catchments. Two measurement indices including NSE and RMSE 210 are shown on the figures. NSEs demonstrate that data driven model is very robust. Based on the literature, 211 when NSE is more than 0.5, predictive skill of the model is highly robust. Minimum NSE in the sub212 catchments is more than 0.9. Thus, model is robust in terms of the NSE. However, using one index might 
213 not be sufficient to authenticate abilities of the data driven model for further applications. RMSEs in the

214 non-urban sub-catchment and urban sub-catchment are 45.2 and $11.7 \mathrm{~L} / \mathrm{s}$ respectively that demonstrate

215 model might be reliable in the most of time steps. However, model might not reliable to predict outflow

216 in very low rate of flows. It should be noted that stormwater management is the main purpose of the

217 proposed framework that means higher outflow might be noticed. Thus, using the developed model is

218 reliable. Area of the simulated sub-catchments is different. Hence, outflow in the non-urban sub-

219 catchment is much higher than other one. Figure 8 displays training and testing process of the data driven

220 model at the outflow point of the catchment. Based on the computed measurement indices, performance

221 of the model in the catchment is robust as well.

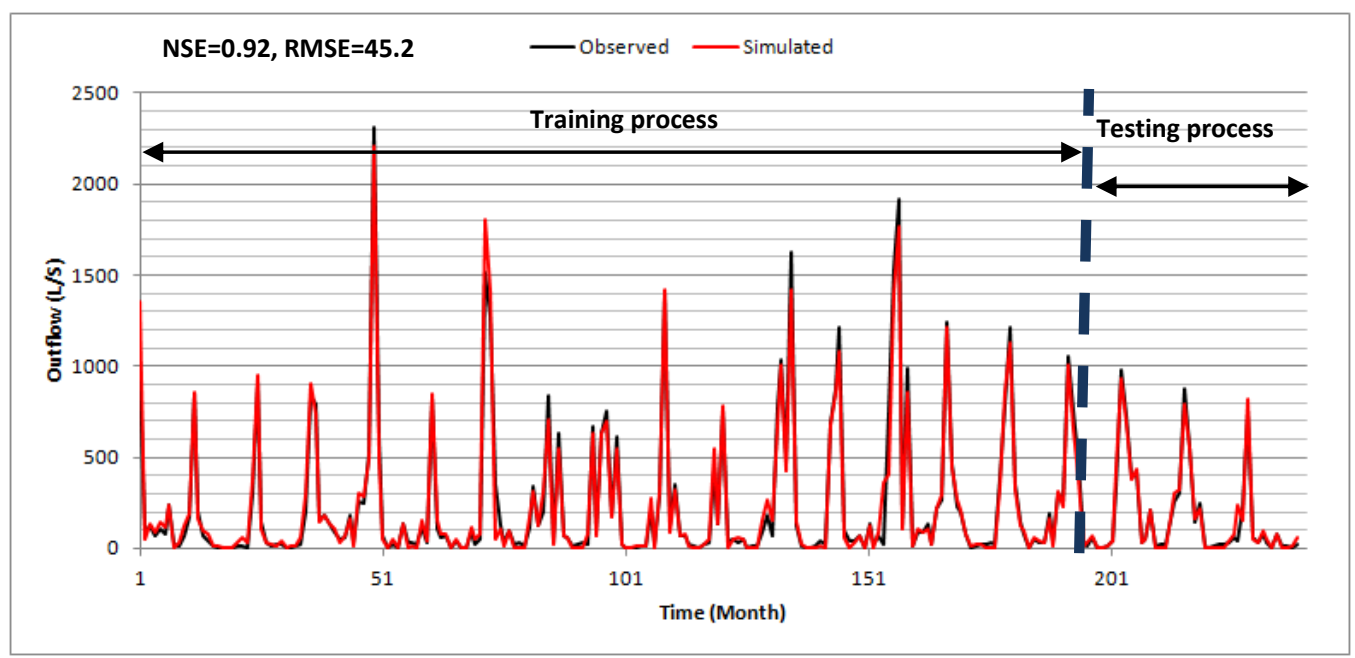

Figure 6- training and testing process of the data driven model in the non-urban sub-catchment 


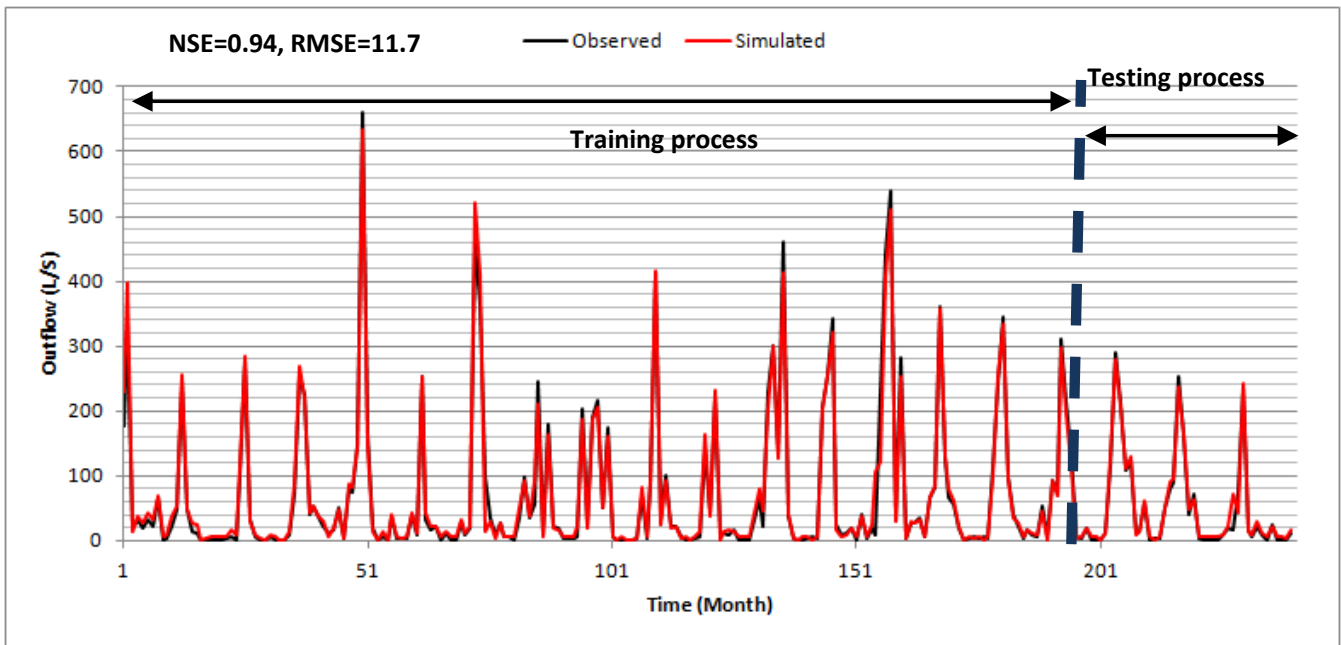

Figure 7- training and testing process of the data driven model in the urban sub-catchment

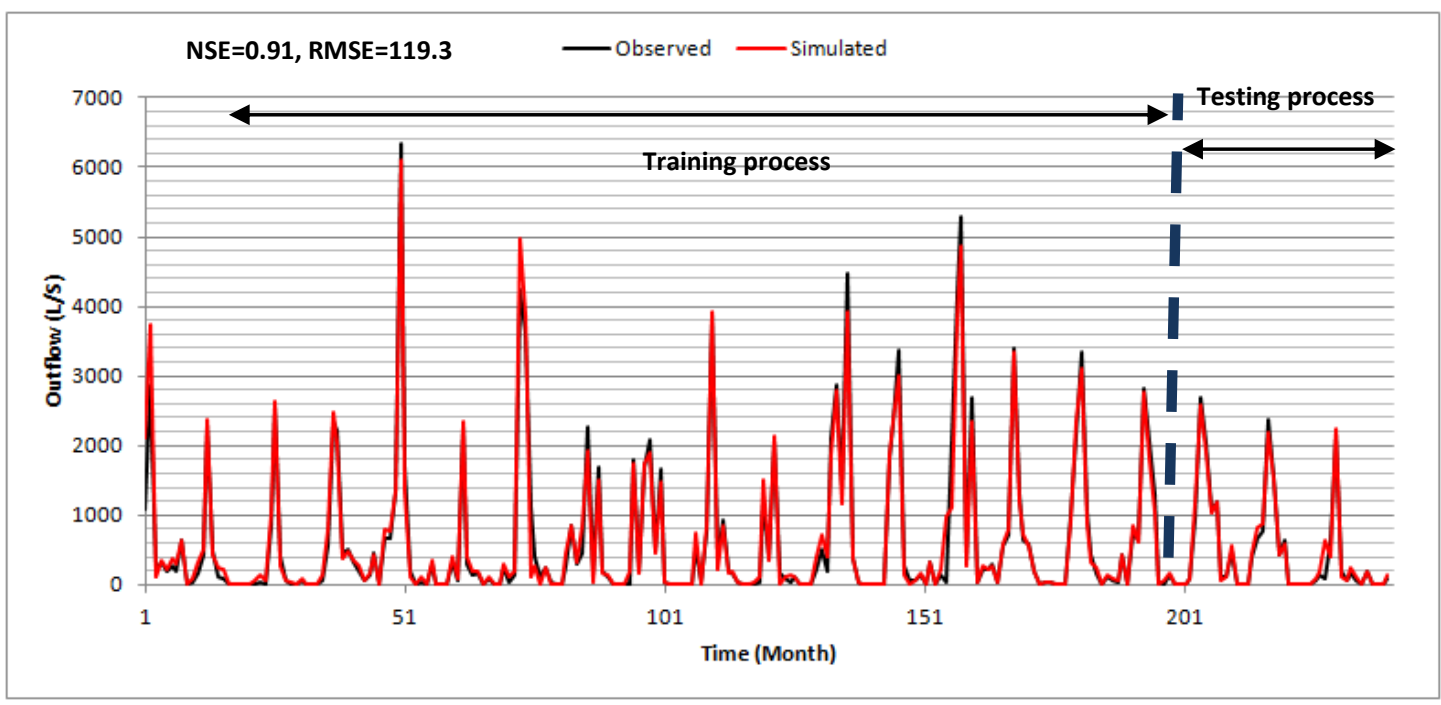

Figure 8- training and testing process of the data driven model in the catchment

228 In the next step, it is necessary to present and discuss on the results of the fuzzy physical habitat

229 simulation at the downstream river ecosystem of the simulated catchment. Table 3 displays developed

230 fuzzy rules for the physical habitat simulation based on the expert opinions and field observations in the

231 river habitats of the studied basin for the target species that is the Brown trout. Figure 9 displays NWUA

232 curve for the downstream river ecosystem of the simulated catchment. 
Table 3- Physical habitat fuzzy rules (L, M and $\mathrm{H}$ mean low, medium and high respectively)

\begin{tabular}{|c|c|c|c|c|}
\hline Rule Code & Depth & Velocity & Substrate & Habitat suitability \\
\hline$B R 1$ & $M$ & $L$ & $M$ & $M$ \\
\hline$B R 2$ & $H$ & $L$ & $M$ & $M$ \\
\hline$B R 3$ & $L$ & $L$ & $M$ & $L$ \\
\hline$B R 4$ & $H$ & $M$ & $H$ & $H$ \\
\hline$B R 5$ & $L$ & $M$ & $H$ & $H$ \\
\hline BR6 & $M$ & $M$ & $H$ & $H$ \\
\hline$B R 7$ & $H$ & $H$ & $L$ & $L$ \\
\hline$B R 8$ & $M$ & $H$ & $L$ & $L$ \\
\hline$B R 9$ & $L$ & $H$ & $L$ & $L$ \\
\hline BR10 & $M$ & $M$ & $M$ & $M$ \\
\hline BRII & $L$ & $M$ & $M$ & $M$ \\
\hline BR12 & $H$ & $M$ & $M$ & $M$ \\
\hline BR13 & $M$ & $H$ & $M$ & $L$ \\
\hline BR14 & $L$ & $H$ & $M$ & $L$ \\
\hline BR15 & $H$ & $H$ & $M$ & $L$ \\
\hline BR16 & $L$ & $L$ & $L$ & $L$ \\
\hline BR17 & $M$ & $L$ & $L$ & $L$ \\
\hline BR18 & $H$ & $L$ & $L$ & $M$ \\
\hline BR19 & $L$ & $L$ & $H$ & $M$ \\
\hline$B R 20$ & $M$ & $L$ & $H$ & $M$ \\
\hline$B R 21$ & $H$ & $L$ & $H$ & $H$ \\
\hline$B R 22$ & $M$ & $M$ & $L$ & $H$ \\
\hline$B R 23$ & $H$ & $M$ & $L$ & $H$ \\
\hline$B R 24$ & $L$ & $M$ & $L$ & $M$ \\
\hline$B R 25$ & $L$ & $H$ & $H$ & $L$ \\
\hline BR26 & $M$ & $H$ & $H$ & $L$ \\
\hline BR27 & $H$ & $H$ & $H$ & $L$ \\
\hline
\end{tabular}




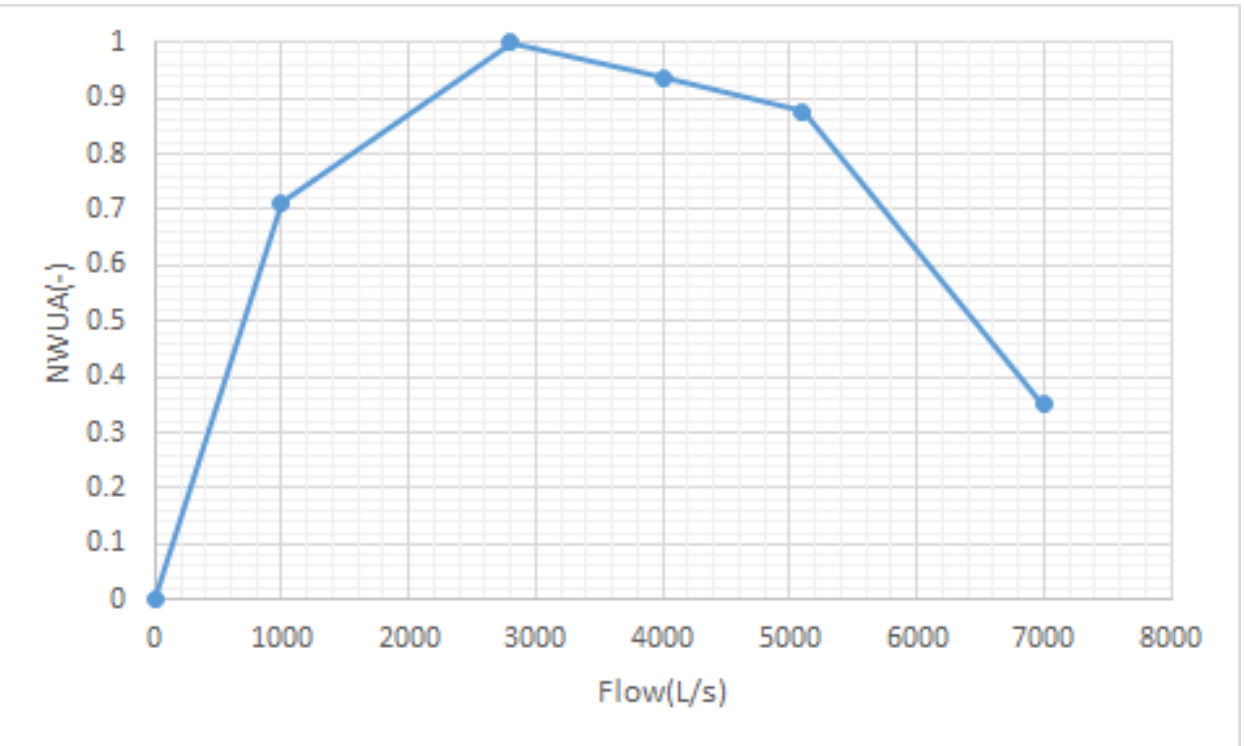

Figure 9- NWUA curve at the downstream river ecosystem of the simulated catchment based on the output of the physical habitat simulation

238 Figure 10 displays normalized non-dominated solutions for the optimization problem by the MOPSO.

239 Selecting the best solution is one of the challenges in the application of the multi-objective algorithms. In

240 the proposed framework, optimal solution should provide a balance between urbanization and physical

241 habitat loss for the fish. Thus, least square difference between normalized solutions was considered as the

242 criterion to select the best response. Based on the figure $7, Z=[46.6245 .82]$ was selected as the best 243 solution in the case study. 




Figure 10- Non- dominate solutions by the MOPSO

246

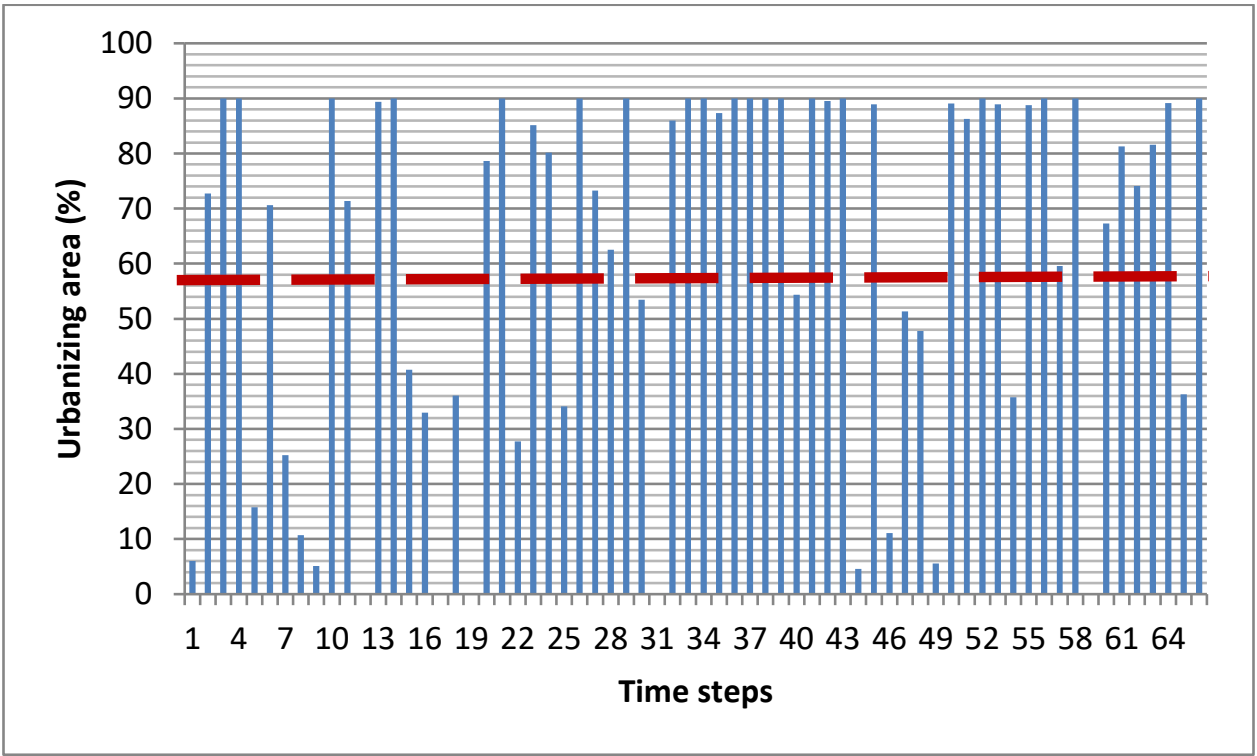

Figure 11- Direct response by the MOPSO 




Figure 12- NWUA in the current condition, initial plan of the urbanization and the optimal plan of the urbanization 


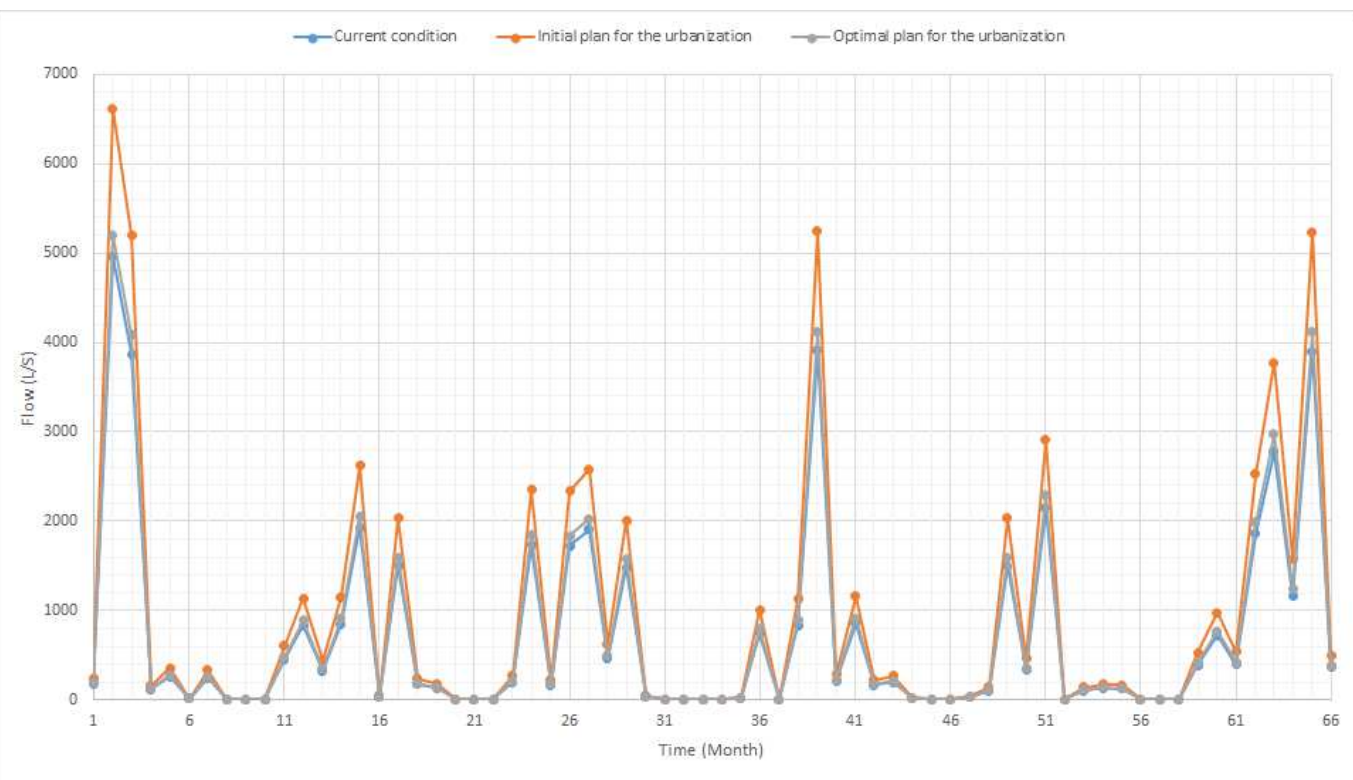

Figure 13- Outflows in the current condition, initial plan of the urbanization and the optimal plan of the urbanization

Figure 11 displays urbanizing area (\%) in different time steps as direct output of the MOPSO. In fact, optimization algorithm presents different areas for the urban region in each time step to achieve the optimal solution. However, it is not useable practically. Because, area of the urban region could not be 261 changed in different months. Hence, it is essential to apply a statistical index to assess the area of the 262 urban region. Arithmetic mean was considered as an index in this regard as displayed by the dash line in 263 the figure 11. Based on this figure, urban areas should be considered as $56 \%$ of the total area of the 264 simulated catchment to minimize physical habitat impacts considering physical habitat loss modeling. In 265 the next step, it is necessary to evaluate optimal plan for the urbanization by the multi-objective 266 optimization.

267 Figure 12 displays the normalized physical habitat loss in three scenarios including current condition, 268 initial plan for the urbanization and optimal plan for the urbanization proposed by the MOPSO. As 269 presented in the previous section, urban area had been planned up to $90 \%$ of the total area in the initial 270 plan. A significant difference between the current condition and the initial plan of the urbanization in 
271 some time steps is a serious threat for the physical habitats. For example, difference between the current

272 condition and the initial plan for the urbanization in the third time step is $20 \%$ approximately that

273 increases physical habitat loss for the fish considerably. In contrast, the difference between optimal plan

274 and the current condition is limited. In fact, the performance of the optimization algorithm seems robust

275 to minimize physical habitat loss. However, more discussion needs using measurement indices. Figure 13

276 displays outflows of the catchment in three scenarios including the current condition, initial plan for the

277 urbanization and optimal plan urbanization. This figure demonstrates that performance of the

278 optimization algorithm is robust as well. Optimal plan reduced surface runoff of the catchment

279 remarkably compared with the initial plan of the urbanization in the case study.

280 In the next step, it is essential to discuss on the different aspects of the results and the proposed 281 framework. Table 3 displays computed measurement indices regarding the performance of the 282 optimization model. RMSEs for the initial plan and the optimal plan are 4.98 and 0.66 respectively. It 283 seems that $4.98 \mathrm{~L} / \mathrm{S}$ is not a significant discharge. However, it should be noted that RMSE might not be a 284 good index in our case study. Because, outflow is low in many time steps. Hence, vulnerability index 285 should be noticed in the cases such as our case study. It might be possible RMSE is an appropriate index 286 in other case studies. Thus, we do not recommend excluding RMSE as a measurement index in the future 287 studies. Vulnerability indices for the initial plan and the optimal plan are $71.66 \%$ and $5.75 \%$ respectively. 288 In fact, vulnerability index demonstrates how the proposed optimization model is able to mitigate 289 physical habitat impacts of the stormwater in the simulated catchment. Vulnerability index in the initial 290 plan indicates that it might be very harmful for the aquatic habitats. Because, maximum physical habitat 291 loss has increased significantly. In fact, it might increase required energy for the fish to swim to the 292 upstream of the river. It might be problematic for the fish to reproduce and search for food when physical 293 habitat loss is high. Conversely, optimal plan is able to decrease physical habitat loss significantly. 294 Because, vulnerability index is $6 \%$ approximately that indicates increasing of the physical habitat loss is 295 not remarkable. A point should be noted regarding the optimal plan. It is able to reduce physical habitat 
loss and increase urban area simultaneously. In fact, results indicate that $56 \%$ for the urbanizing area is more than half of the initial plan that was $90 \%$ of the total area. In other words, it might reduce negotiation between regional government and environmental advocators regarding the development of the urban area in the simulated catchment. Hence, we recommend utilizing the proposed framework in the future studies to optimize area of the developing urban region in the catchments considering physical habitat impacts by applying physical habitat loss modeling as an advanced method in this regard

It is necessary to discuss on the different aspects of the proposed framework. First, we should discuss on why the proposed method or mechanism might be appropriate for the practical projects. Using an ANFIS based model to simulate runoff in the catchment and sub-catchment scale is possible to apply the runoff model in the structure of the optimization algorithms. It should be noted available hydrodynamic and hydrologic models to simulate surface runoff in the urban and non-urban catchments are not useable in the structure of the optimization algorithm directly. In fact, in the conventional urban water management, different scenarios might be simulated. Then, they will be analyzed in the structure of a decision-making system. However, the proposed method provides a flexible environment to optimize urban area. Moreover, our method considered the physical habitat impacts by application of one of the most advanced methods in the assessment of physical habitats. It should be noted that the previous models lack the physical habitat component in their structure that might be a significant drawback. Because, not only would the physical habitat loss be important in the streams, but it might also be more sensitive compared with water quality factors in some cases. Thus, the proposed method is able to cover this weakness point for the future studies. Furthermore, using MOPSO is an advantage for the proposed framework. In fact, the developed multi-objective optimization system is able to reduce concerns for the regional

317 governments and environmental advocators simultaneously. MOPSO is a robust algorithm that is able to 318 provide optimal solution for the problem properly. It should be noted limited number of the multiobjective algorithms have been developed in the literature. MOPSO is one of the robust algorithms that has been applied in many engineering branches. It seems that simulation frameworks are not able to cover 
321 complex needs for environmental engineering. In fact, there is a serious conflict between environment and

322 development that might be intensified in the future years due to increasing population. Hence, it is 323 required to use robust simulation-optimization frameworks. Using optimization systems might reduce 324 required time to make decisions. Because, numerous simulations and making decisions based on the 325 result of the simulations might be time consuming. Moreover, absence of using optimization system 326 might weaken accuracy of decisions regarding the development of the urban areas in the catchments.

327 We discussed on the advantages of the proposed framework in the previous paragraph. However, each 328 new method or model might have some disadvantages and limitations that should be considered in 329 practice. The main limitation of the proposed framework is computational complexities. In the computer 330 science, computational complexities are defined as the needed time or memory for an algorithm. The 331 proposed method is a complex algorithm. Because, it utilizes the ANFIS based model in the structure of 332 the multi-objective optimization. In fact, a multi-objective optimization needs more time and memory 333 compared with single objective optimizations. We added an ANFIS model in the optimization process 334 that might increase computational time significantly. In the case study, we simulated a limited time. 335 However, it needed several hours for simulation. It should be noted that numerous simulations336 optimizations or covering a long-term is required in a practical project. Thus, high computational 337 complexities might be a weakness point for the proposed methods. We recommend improving the 338 proposed framework by a focus on the reducing computational complexities in the future studies. The 339 proposed method might open a new window in the urban water management considering complex and 340 unknown environmental aspects such as physical habitat impacts. In fact, the proposed method 341 demonstrates that artificial intelligence or soft computing methods might play a key role in the future of 342 the environmental and water resource engineering. 


\begin{tabular}{|c|c|c|}
\hline & Initial Plan & $\begin{array}{c}\text { Optimal } \\
\text { plan }\end{array}$ \\
\hline $\begin{array}{c}\text { Vulnerability } \\
\text { index (\%) }\end{array}$ & 71.66 & 5.75 \\
\hline RMSE & 4.98 & 0.66 \\
\hline
\end{tabular}

\section{4- Conclusions}

348 Present study proposed a novel framework to optimize the area of the developing urban area in a 349 catchment scale considering physical habitat impacts. We applied PSO-ANFIS framework to simulate 350 runoff. Testing process of the model was carried out in the sub-catchment and catchment scale. Moreover, 351 fuzzy physical habitat modeling as one of the novel methods was utilized to model the physical habitat 352 impacts in the structure of a multi-objective optimization. MOPSO was used to optimize the area of the 353 developing urban region. Based on the results in the case study, initial plan for the urbanization might 354 damage physical habitat at downstream river drastically. However, the optimal plan proposed by the new 355 method is able to minimize impacts of the physical habitat loss. Initial plan considered to increase the 356 urban area to $90 \%$ of the total area. However, the optimal plan proposed $56 \%$ as the optimal area for the 357 urbanization considering environmental impacts in the physical habitats.

\section{5- Declarations}

\section{$359 \quad$ Funding}

360 Not applicable

\section{Conflicts of interest/Competing interests}

362 None 
364 Some or all data used are available from the corresponding author by request.

\section{Code availability}

Code is available. However, it is not free of charge

\section{Authors' contributions}

Methodology, calculations and draft version by the first author. Field studies and review by the second author

\section{References}

Adnan, R.M., Liang, Z., Kuriqi, A., Kisi, O., Malik, A. and Li, B., 2020, October. Streamflow forecasting using heuristic machine learning methods. In 2020 2nd International Conference on Computer and Information Sciences (ICCIS) (pp. 1-6). IEEE.

Afshar, A., Haddad, O.B., Mariño, M.A. and Adams, B.J., 2007. Honey-bee mating optimization (HBMO) algorithm for optimal reservoir operation. Journal of the Franklin Institute, 344(5), pp.452-462. Azamathulla, H.M., Chang, C.K., Ghani, A.A., Ariffin, J., Zakaria, N.A. and Hasan, Z.A., 2009. An ANFIS-based approach for predicting the bed load for moderately sized rivers. Journal of HydroEnvironment Research, 3(1), pp.35-44.

Bovee, K.D., Lamb, B.L., Bartholow, J.M., Stalnaker, C.B. and Taylor, J., 1998. Stream habitat analysis using the instream flow incremental methodology. GEOLOGICAL SURVEY RESTON VA

\section{BIOLOGICALRESOURCES DIV.}

Coello, C.A.C., Pulido, G.T. and Lechuga, M.S., 2004. Handling multiple objectives with particle swarm optimization. IEEE Transactions on evolutionary computation, 8(3), pp.256-279.

Dalkiliç, H.Y. and Hashimi, S.A., 2020. Prediction of daily streamflow using artificial neural networks (ANNs), wavelet neural networks (WNNs), and adaptive neuro-fuzzy inference system (ANFIS) models. Water Supply, 20(4), pp.1396-1408. 

metaheuristic algorithms. Computers \& Industrial Engineering, 137, p.106040.

Ehteram, M., Karami, H., Mousavi, S.F., Farzin, S., Celeste, A.B. and Shafie, A.E., 2018. Reservoir operation by a new evolutionary algorithm: Kidney algorithm. Water resources management, 32(14), 391 pp.4681-4706.

392 Gironás, J., Roesner, L.A., Rossman, L.A. and Davis, J., 2010. A new applications manual for the Storm 393 Water Management Model (SWMM). Environmental Modelling \& Software, 25(6), pp.813-814.

394 Gupta, H.V., Kling, H., Yilmaz, K.K. and Martinez, G.F., 2009. Decomposition of the mean squared error 395 and NSE performance criteria: Implications for improving hydrological modelling. Journal of hydrology, $396 \quad 377(1-2)$, pp.80-91.

397 Haddad, O.B, Karimirad, I., Seifollahi-Aghmiuni, S. and Loáiciga, H.A., 2015. Development and 398 application of the bat algorithm for optimizing the operation of reservoir systems. Journal of Water 399 Resources Planning and Management, 141(8), p.04014097.

400 Haddad, O.B., Hosseini-Moghari, S.M. and Loáiciga, H.A., 2016. Biogeography-based optimization 401 algorithm for optimal operation of reservoir systems. Journal of Water Resources Planning and 402 Management, 142(1), p.04015034.

403 Jefferson, A.J., Bhaskar, A.S., Hopkins, K.G., Fanelli, R., Avellaneda, P.M. and McMillan, S.K., 2017.

404 Stormwater management network effectiveness and implications for urban watershed function: A critical 405 review. Hydrological Processes, 31(23), pp.4056-4080.

406 Kisi, O. and Kerem Cigizoglu, H., 2007. Comparison of different ANN techniques in river flow 407 prediction. Civil Engineering and Environmental Systems, 24(3), pp.211-231.

408 Kong, F., Ban, Y., Yin, H., James, P. and Dronova, I., 2017. Modeling stormwater management at the 409 city district level in response to changes in land use and low impact development. Environmental $410 \quad$ Modelling \& Software, 95, pp.132-142. 
411 Mehr, A.D., Kahya, E., Şahin, A. and Nazemosadat, M.J., 2015. Successive-station monthly streamflow

412 prediction using different artificial neural network algorithms. International Journal of Environmental

413 Science and Technology, 12(7), pp.2191-2200.

414 Mirjalili, S., Dong, J.S., Sadiq, A.S. and Faris, H., 2020. Genetic algorithm: Theory, literature review, and 415 application in image reconstruction. Nature-inspired optimizers, pp.69-85.

416 Montaseri, M., Afshar, M.H. and Bozorg-Haddad, O., 2015. Development of simulation-optimization

417 model (MUSIC-GA) for urban stormwater management. Water resources management, 29(13), pp.4649-

4184665.

419 Noack, M., Schneider, M. and Wieprecht, S., 2013. The Habitat Modelling System CASiMiR: A 420 Multivariate Fuzzy-Approach and its Applications. Ecohydraulics: an integrated approach, 421 pp.75-91.

422

423 Niu, W.J. and Feng, Z.K., 2021. Evaluating the performances of several artificial intelligence methods in 424 forecasting daily streamflow time series for sustainable water resources management. Sustainable Cities 425 and Society, 64, p.102562.

426 Riahi-Madvar, H., Dehghani, M., Memarzadeh, R. and Gharabaghi, B., 2021. Short to Long-Term

427 Forecasting of River Flows by Heuristic Optimization Algorithms Hybridized with ANFIS. Water

428 Resources Management, pp.1-18.

429 Sedighkia, M., Abdoli, A. and Datta, B., 2021. Optimizing monthly ecological flow regime by a coupled

430 fuzzy physical habitat simulation-genetic algorithm method. Environment Systems and Decisions, pp.1-

$431 \quad 12$.

432 Sedighkia, M., Datta, B. and Abdoli, A., 2021. Minimizing physical habitat impacts at downstream of

433 diversion dams by a multiobjective optimization of environmental flow regime. Environmental Modelling

434 \& Software, p.105029.

435 Shishegar, S., Duchesne, S. and Pelletier, G., 2018. Optimization methods applied to stormwater 436 management problems: a review. Urban Water Journal, 15(3), pp.276-286. 
437 Yang, X.S. and He, X., 2013. Bat algorithm: literature review and applications. International Journal of 438 Bio-inspired computation, 5(3), pp.141-149. 
Figures



Figure 1

Simple structure of ANFIS based data driven model 

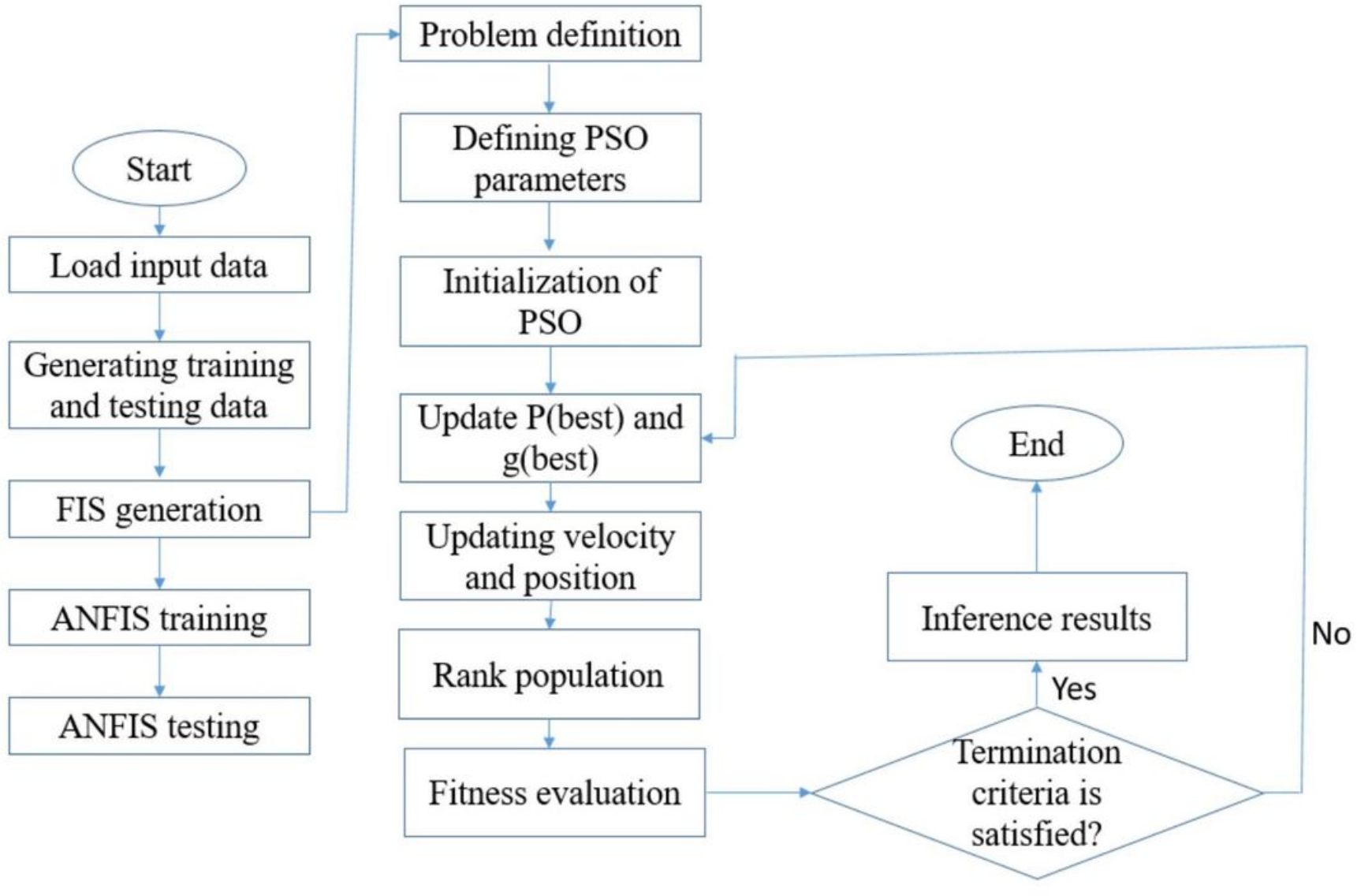

Figure 2

PSO-ANFIS flowchart

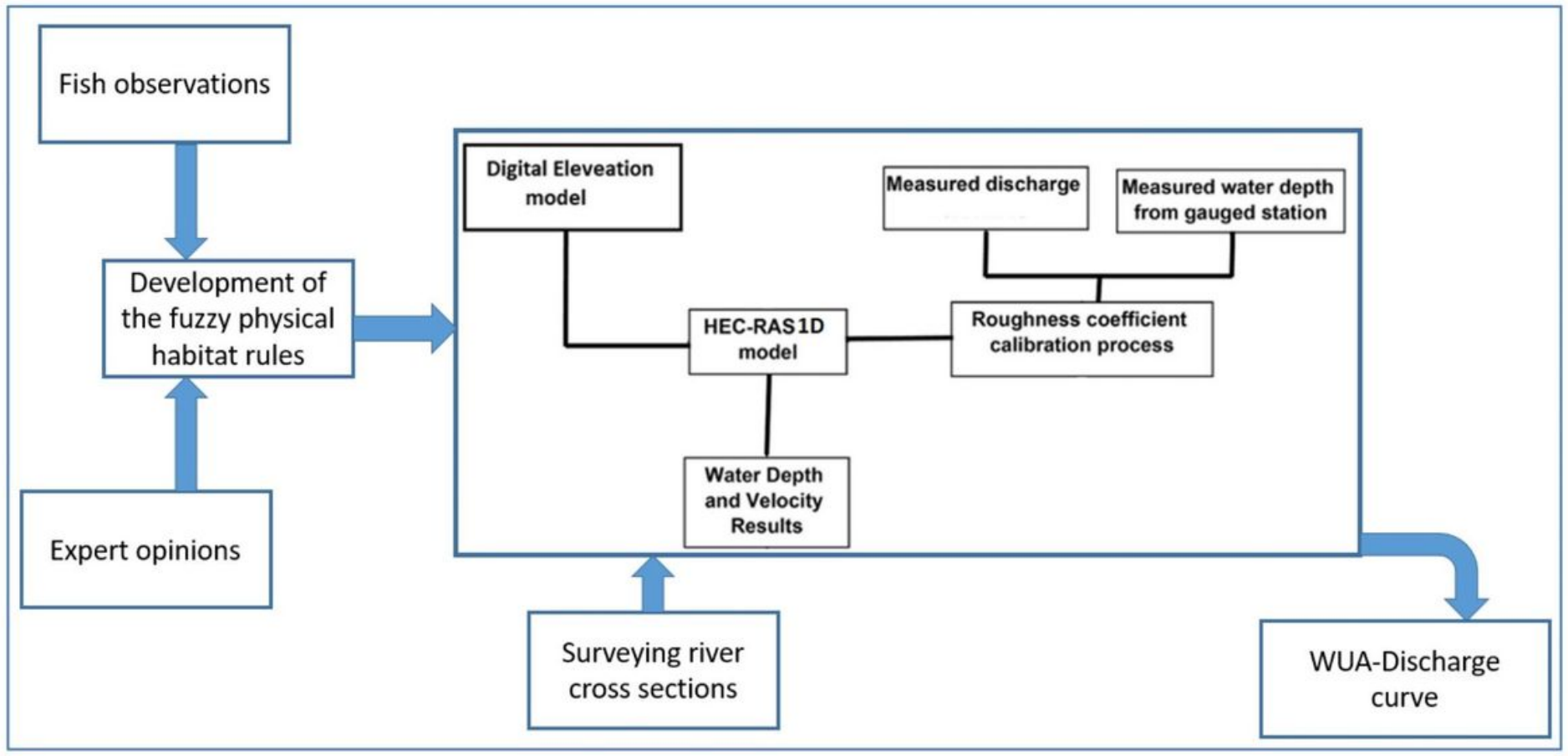


Figure 3

flowchart of the physical habitat simulation in the proposed framework

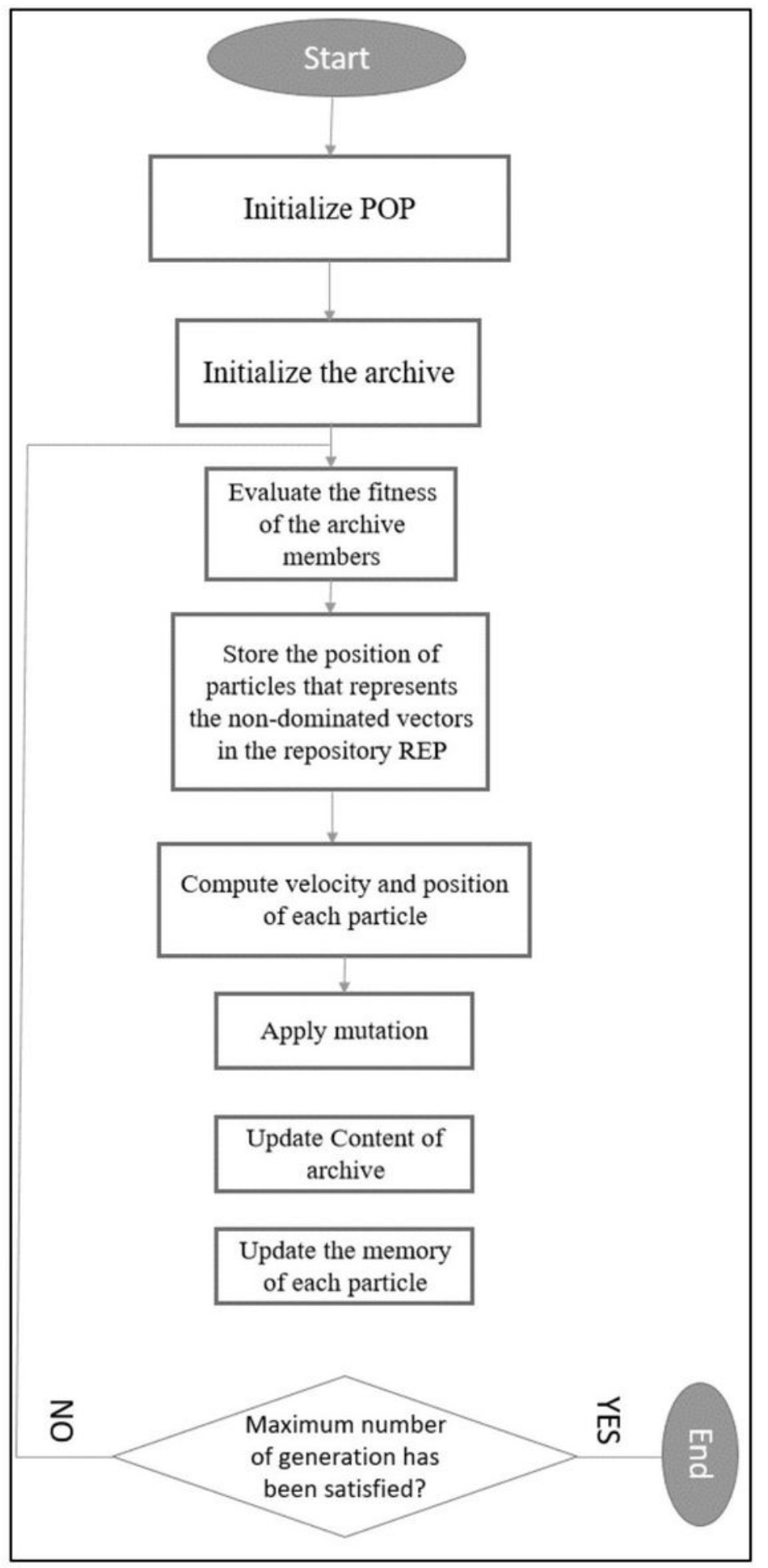

Figure 4

mutilobjective Particle swarm optimization (MOPSO) flowchart 


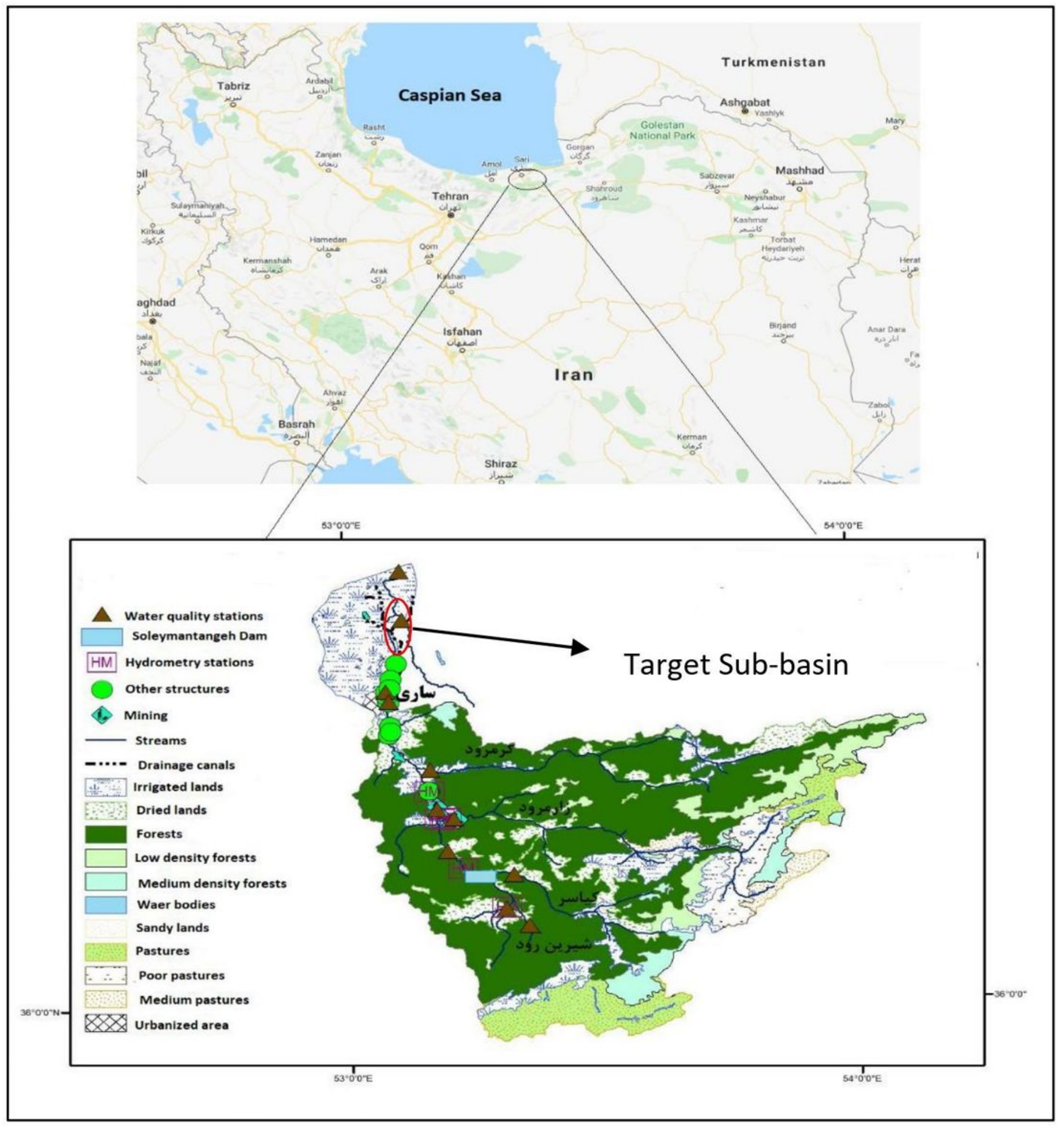

\section{Figure 5}

Land use, location of the Rajaei reservoir and river network map of Tajan basin Note: The designations employed and the presentation of the material on this map do not imply the expression of any opinion whatsoever on the part of Research Square concerning the legal status of any country, territory, city or area or of its authorities, or concerning the delimitation of its frontiers or boundaries. This map has been provided by the authors. 


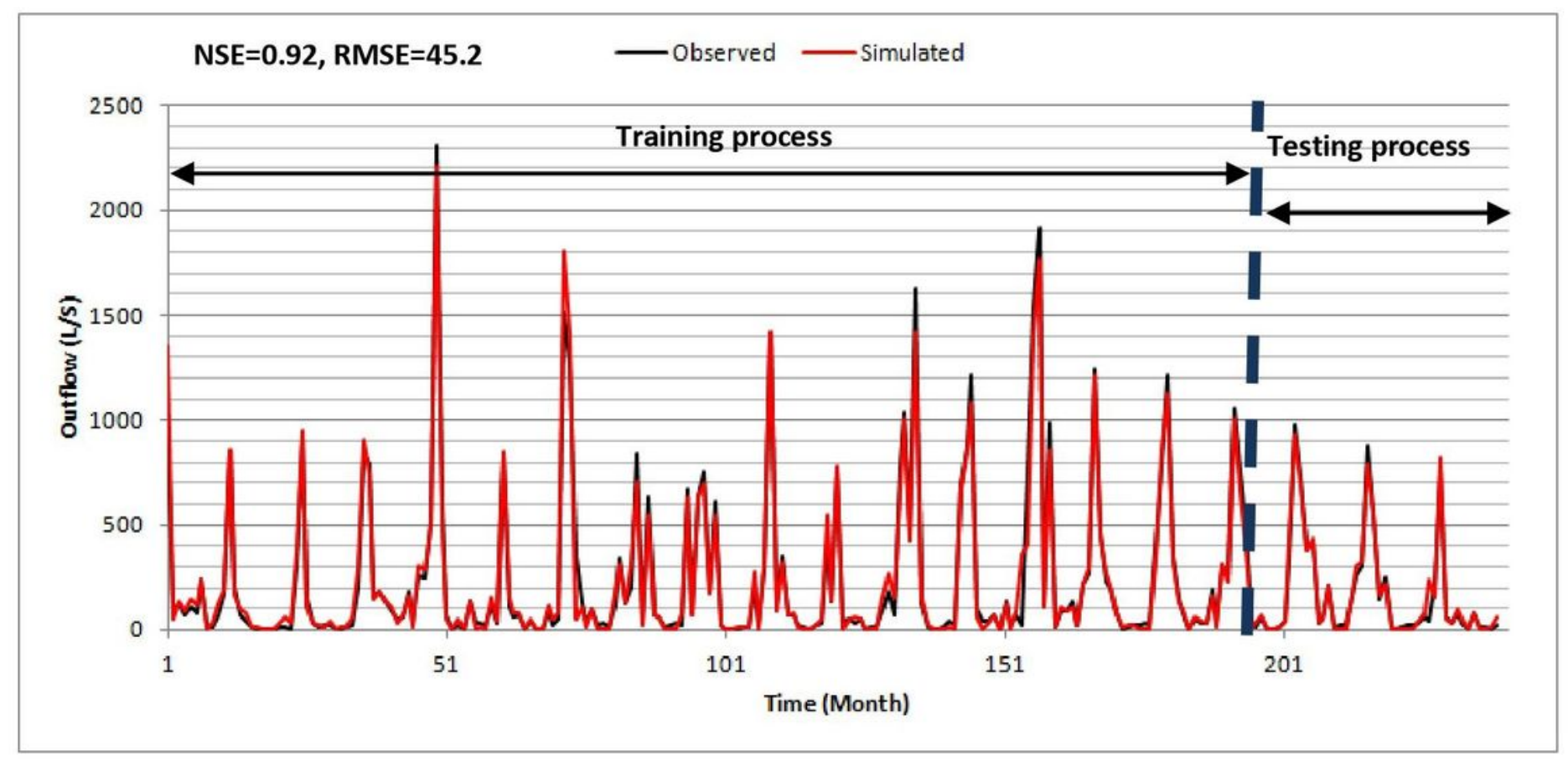

Figure 6

training and testing process of the data driven model in the non-urban sub-catchment

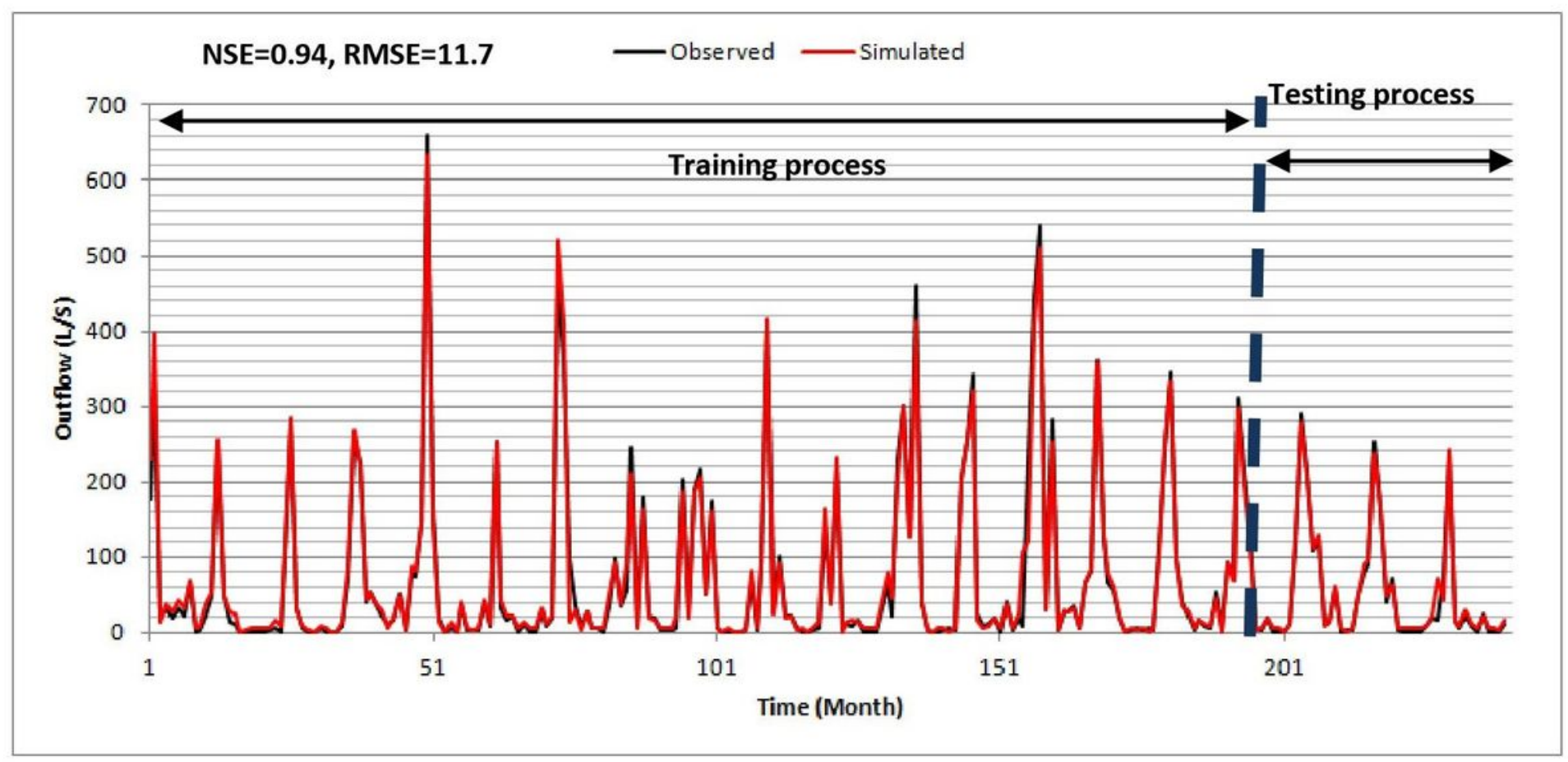

Figure 7

training and testing process of the data driven model in the urban sub-catchment 


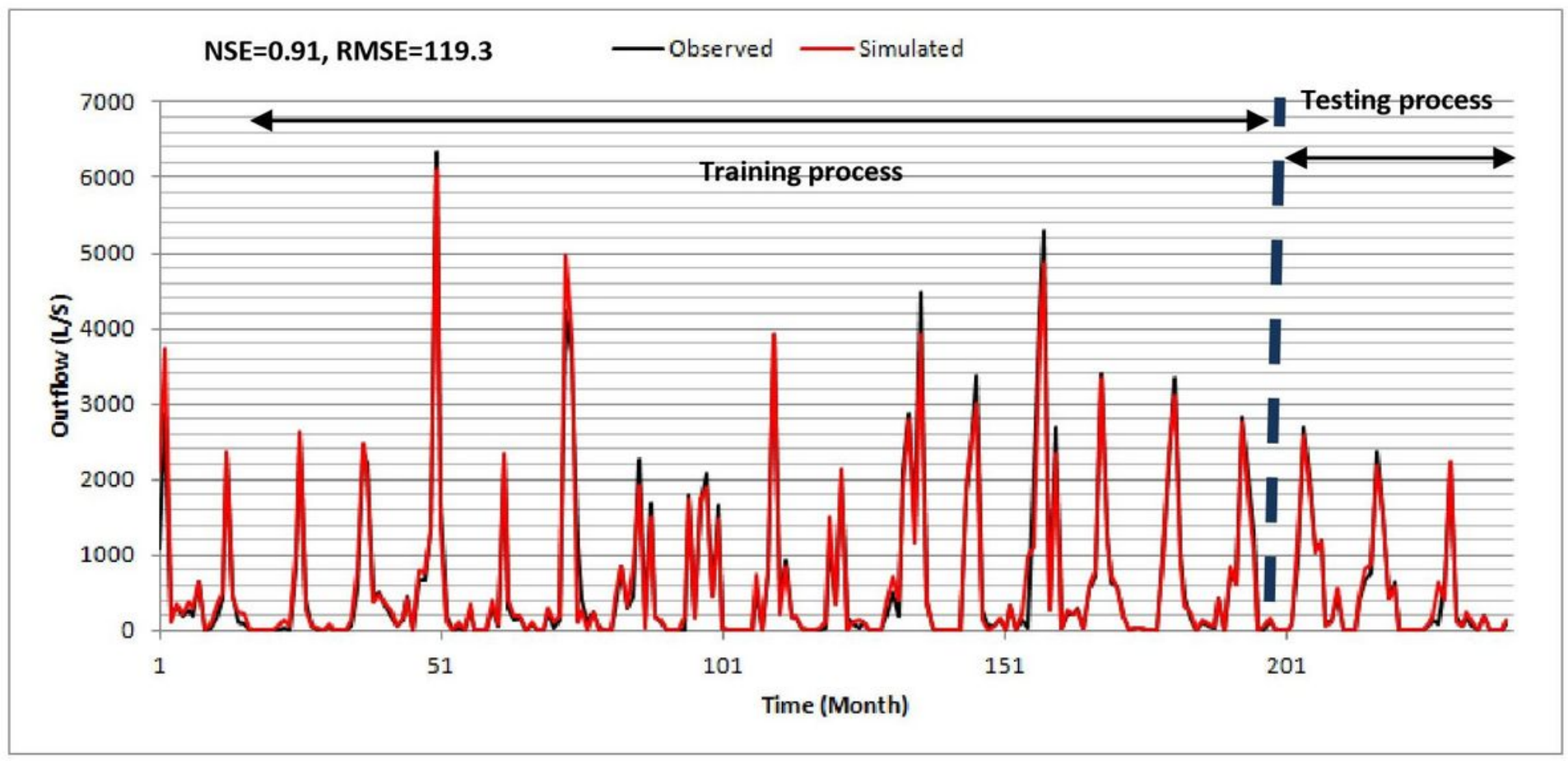

Figure 8

training and testing process of the data driven model in the catchment



Figure 9 
NWUA curve at the downstream river ecosystem of the simulated catchment based on the output of the physical habitat simulation

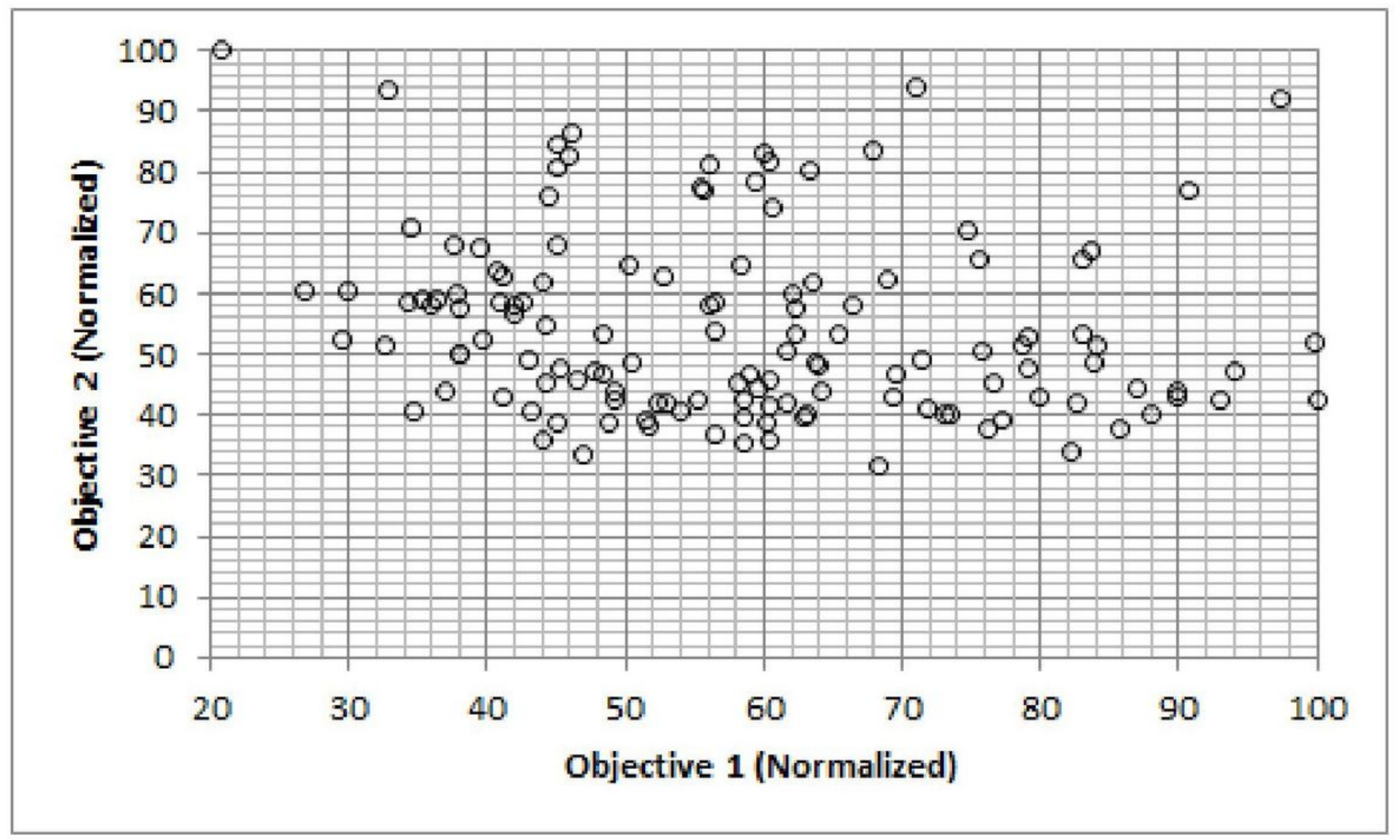

Figure 10

Non- dominate solutions by the MOPSO 




Figure 11

Direct response by the MOPSO 


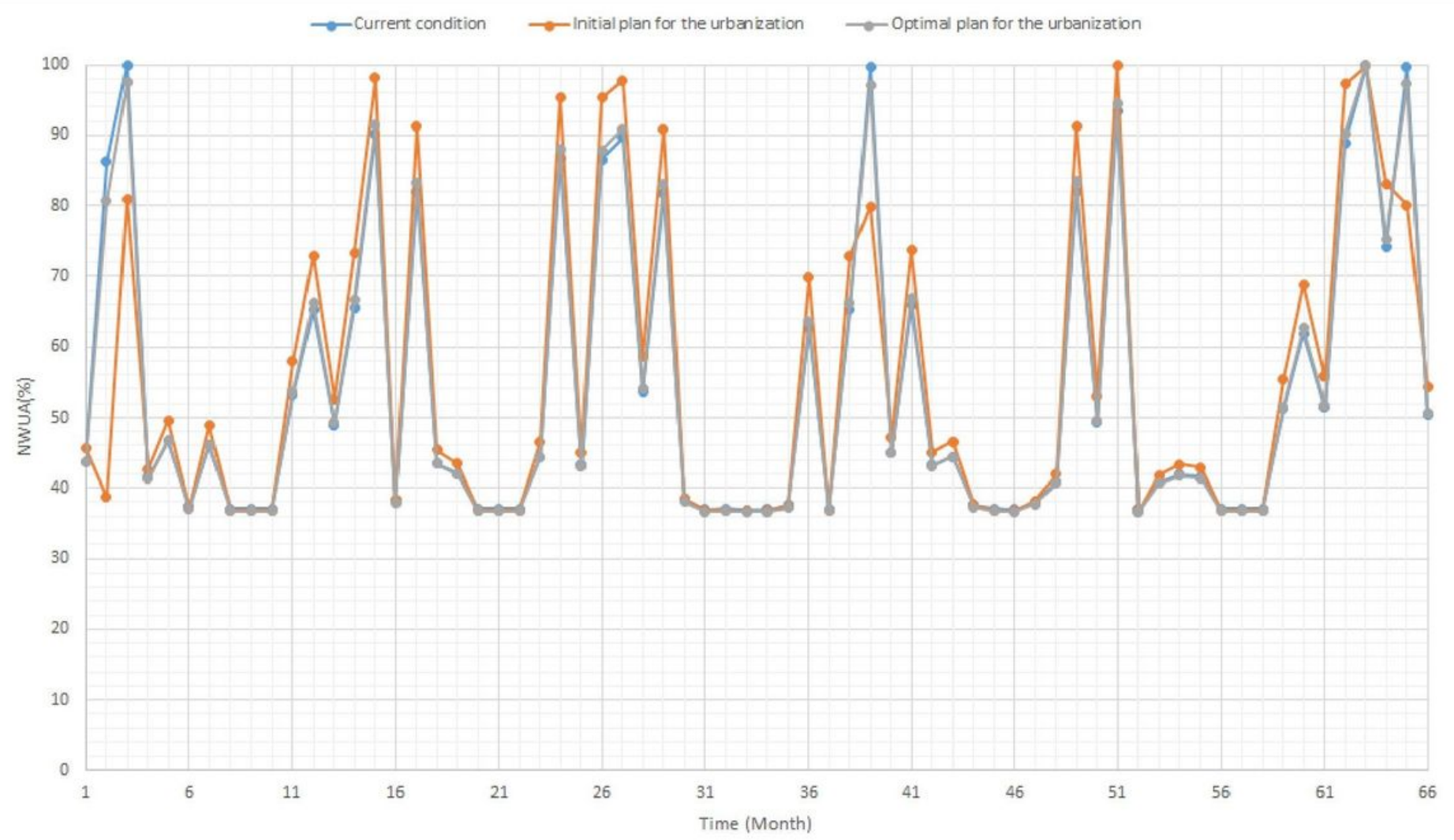

Figure 12

NWUA in the current condition, initial plan of the urbanization and the optimal plan of the urbanization

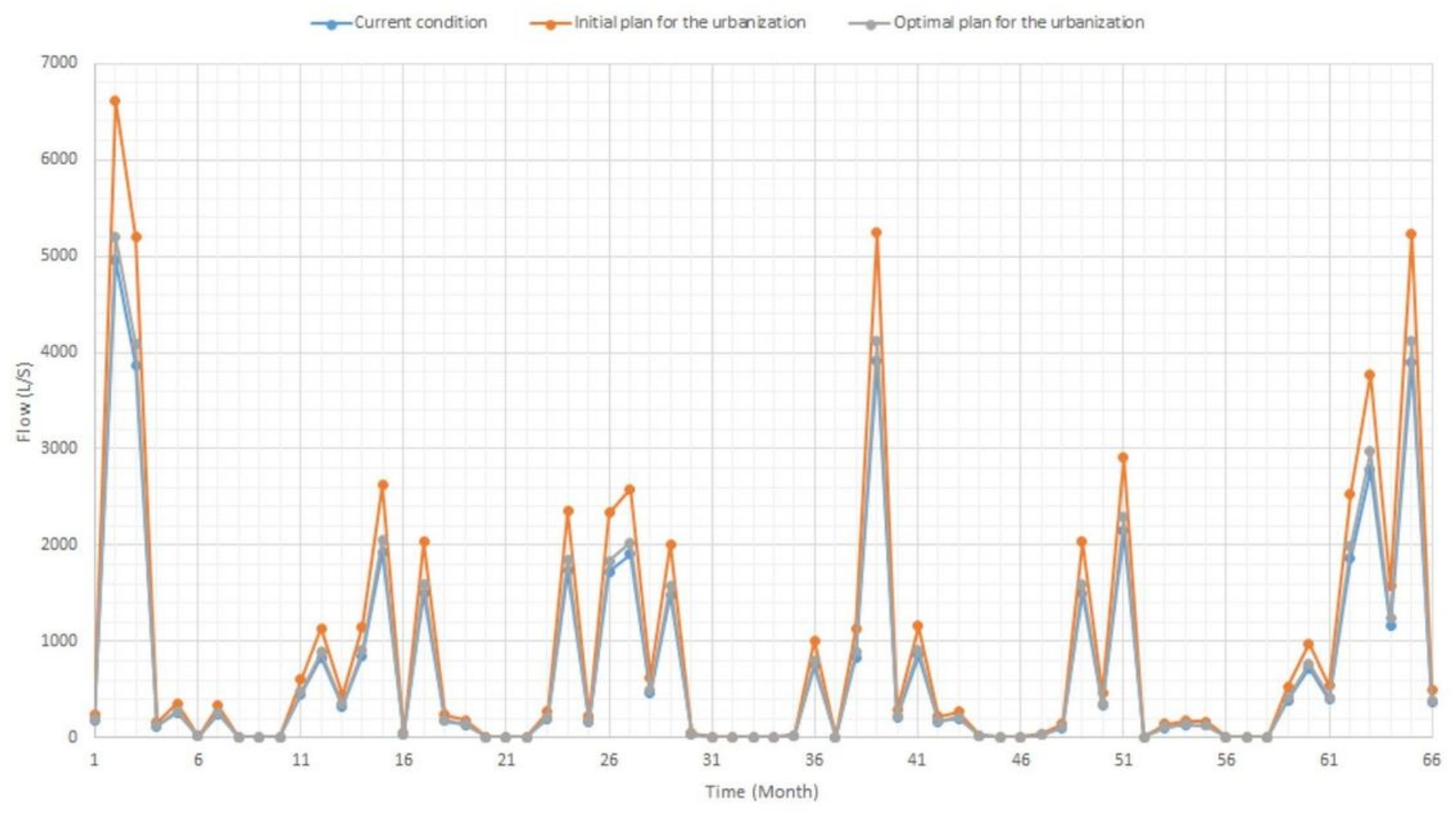


Figure 13

Outflows in the current condition, initial plan of the urbanization and the optimal plan of the urbanization 